\title{
Malaysian State Sports Schools Football Coaching Process Key Themes Development: Constant Comparison Method in Data Analysis
}

\author{
Ramesh Ram Ramalu*, Zulakbal Abd Karim and Gunathevan Elumalai \\ Department of Coaching Science, Faculty of Sports Science and Coaching, Universiti Pendidikan Sultan Idris, \\ 35900 Tanjong Malim, Perak, Malaysia
}

\begin{abstract}
This study compares the Malaysian coaching process's key development themes with Cote and Gilbert's (2009) Effective Coaching Model in Malaysian football development. The participant selection is based on purposive sampling involving fourteen head coaches from State Sports Schools throughout Malaysia. In addition, an in-depth semi-structured interview with open-ended questions was carried out and analysed following Glaser and Strauss's constant comparative method (1967). Based on the analysis, the following seven new development themes have emerged in the context of the Malaysian coaching process as compared to Cote and Gilbert, Effective Coaching Model: i) signature coaching, ii) risk management, iii) fun elements, iv) empowerment, v) spirituality, vi) life skills and vii) coaching intervention. Subsequent exploration is recommended to identify how this knowledge is integrated into the coaching process and applied in the Malaysian football development program.
\end{abstract}

Keywords: Coaching process, effective coaching, football, key development themes

\begin{tabular}{|c|c|}
\hline & INTRODUCTION \\
\hline ARTICLE INFO & $\begin{array}{l}\text { The Football Association of Malaysia } \\
\text { (FAM) has always been of great importance }\end{array}$ \\
\hline Article history: & elopment of young players for \\
\hline $\begin{array}{l}\text { Received: } 08 \text { March } 2021 \\
\text { Accepted: } 05 \text { August } 2021\end{array}$ & the future of football in Malaysia. Since \\
\hline Published: 15 September 2021 & the $1980 \mathrm{~s}$, various development programs \\
\hline DOI: https://doi.org/10.47836/pjssh.29.3.04 & have been developed and implemented. \\
\hline $\begin{array}{l}\text { E-mail addresses: } \\
\text { ramesh@mbsskl.edu.my (Ramesh Ram Ramalu) } \\
\text { zulakbal@fsskj.upsi.edu.my (Zulakbal Abd Karim) } \\
\text { gunathevan@fsskj.upsi.edu.my (Gunathevan Elumalai) } \\
{ }^{*} \text { Corresponding author }\end{array}$ & $\begin{array}{l}\text { These programs are continuously being } \\
\text { strengthened and revised to suit the prevailing } \\
\text { conditions (Holmes, 2018). Football is }\end{array}$ \\
\hline
\end{tabular}


regulated at the grassroots level, along with the Football Association of Malaysia (FAM), the Ministry of Youth and Sports (KBS), the National Sports Council (MSN) and the Ministry of Education of Malaysia (KPM), by producing a program known as the National Football Development Program (NFDP; Karim \& Razak, 2018). The NDP aims to create an organised and systematic framework for football development to increase the quantity and standard and create great national football teams.

The mission of FAM is to have a power structure with the requisite consistency for many players who are technically, tactically, physiologically and psychologically capable (Kassim \& Che Ali, 2015). It is estimated that there are currently almost 23,000 trainees in 123 centres or academies around the country. Thus, it covers trainees aged 7 to 17 , taught by 1,025 full-time and part-time coaches. Nevertheless, the goal of the NFDP was to hit 55,000 trainees by 2020 (Karim \& Razak, 2018). It is also controversial to look at these 55,000 trainees' effects if the coaching process is inefficient. Coach development is a primary concern, according to Kassim and Boardley (2018), to set up national standard support for coach education before the organised framework of preparing trained coaches. It is meant to build consensus for the national standard for coaching teaching before the comprehensive structure for the preparation of qualified coaches. In every learning and development scheme, the primary factor in the coaches' quality is more important than a good syllabus, standardised coaching process, special equipment or state-of-theart venue (Crawford et al., 2017).

The current study examines all the ingredients of success or key development themes practised by head coaches directly involved with the football development under the NFDP program. The study is also to see whether the findings of these key development themes are in line with the other models of effective coaching process that are widely used in other sports (Fairs, 1987; Franks et al., 1988; Sherman et al., 1997; Lyle, 2002). However, according to Kassim (2014), although all these models have real advantages, but almost all coaching processes do not lead to different environmental perspectives. Although this research referred to many models, the attention is more focused on the Effective Coaching Model of Cote and Gilbert (2009) to look at the similarities and differences from an external perspective. Cote and Gilbert (2009) developed a framework for coaching effectiveness that takes into account the reasons listed above and gives insight into the key components that should be in place for effective coaching: i) the knowledge of coaches; ii) the outcomes of athletes, and iii) the context of coaching. Based on the definition of effective coaching by Cote and Gilbert (2009), it is important to consistently utilise the knowledge of coaches to enhance the confidence, competence, connections and character of athletes given the basic characteristics of a sports background, such as goals, age group, and coaching domain (Cote \& Gilbert, 2009; Flett et al., 2016). Philosophy is needed to 
move the field forward, which clarifies how coaches dynamically communicate with the learning situations they experience, effectively implement and create information that incorporates and alters their current biography as a whole and links it to situated behaviour.

From the gap study stated by researchers from abroad and within the country, whether the existing development themes in the football development program include the needs of current Malaysian coaches coaching perspective. This study's gap became strong when the NFDP, undergoing the first phase of development 2014-2020, failed to qualify for the 2019 FIFA Under-17 World Cup, the first vision of the key performance index (KPI). After NFDP failed in its first hurdle of reaching the 2019 FIFA Under-17
World Cup, the program was called into question what and where it should go from now ("Teong Kim earns", 2018). Therefore, this study aims to gather more information and identify the differences between the coaching process key themes in Malaysian football development with Cote and Gilbert's (2009) effective coaching model. Thus, this framework (see Figure 1) represents the overall direction of this study guided by the literature review and research methodology in answering the research question.

\section{METHODS}

The qualitative methodology allowed interviews to be richly descriptive (Creswell, 2014; Lebar, 2014). The data confirmed the resulting findings of usually replicated

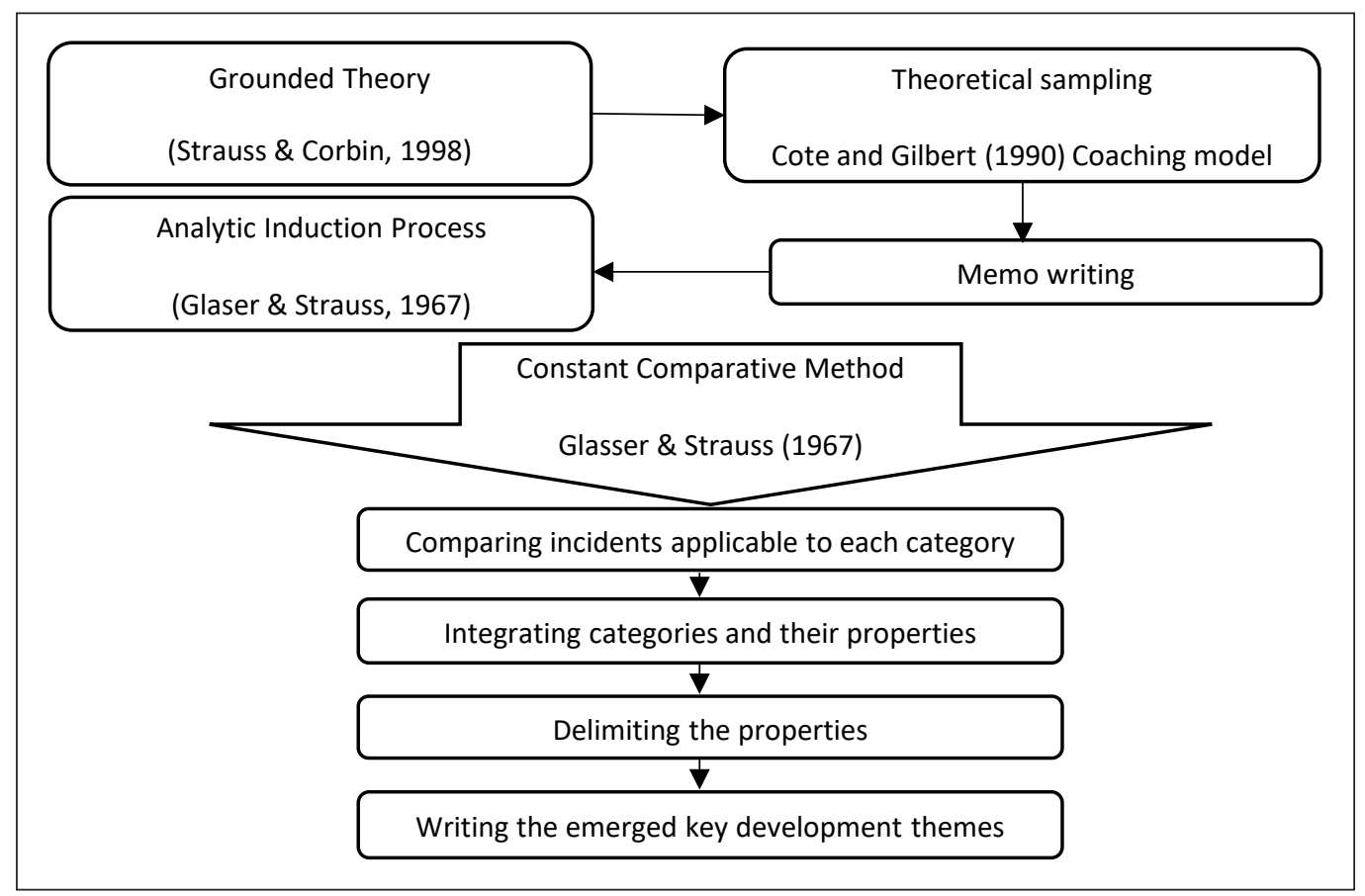

Figure 1. Represents the conceptual framework of the study 
patterns. This researcher wants a richer and more descriptive understanding of the recognition and commitment of information in coaching practice to help explain this choice for a qualitative methodology and illustrate in the phase they require. Qualitative analysis methodology needs to be compared with its polar opposite methodology. By defining the 'Grounded Theory' analysis method as the configuration of a theory based on the data gathered, Neuman (2006) concurs with such an interpretation. The researcher concludes that a qualitative approach to Grounded Theory methodology will help serve this research study.

\section{Participants and Sampling}

There are fourteen Malaysian State Sports School which undergoing football training for those under 16 and 18. Approximately these fourteen schools were provided with two to three coaches, including the head coach and two assistant coaches. Considering that the head coach is the decision-maker in designing every football development program at the State Sports School, participants are all the head coaches recruited. Therefore, the researcher was driven, specifically from a participant recruiting perspective, by stratified purpose sampling with the combination of theoretical sampling techniques as suggested by Patton (2002) and Strauss and Corbin (1990). To identify and choose information-rich cases related to the phenomena of interest, at first, the researcher guided by stratified purposive sampling chooses his individuals as part of his analysis. Strauss and Corbin (1990) define theoretical sampling as the data collection method for producing theory; thus, the researchers gathered codes and analyses and chose which data to collect next to reinforce the theory as it appears. Therefore, the research starts with purposeful sampling and analysis of the following data collection phase with the sample the phenomenon arises and where the theoretical sampling begins.

\section{Sampling Procedure}

Fourteen state sports schools are divided into five zones to launch this sampling process. Peninsular Malaysia has four regions: the north coast (Perlis, Penang and Kedah), the south coast (Johor, Melaka and Negeri Sembilan), the east coast (Pahang, Terengganu and Kelantan), the west coast (Perak, Selangor and Kuala Lumpur) and East Malaysia (Sabah and Sarawak). After classifying all state sports schools into five regions, the researcher arbitrarily decided to schedule an open-ended semistructured data collection interview. The data collection analysis occurs concurrently, iteratively, under Glasser and Strauss's (1967) principle, and the continuous comparison of new data with previous data occurs during the theoretically guided data collection following the initial purposive selected participants. Theoretical sampling is employed until theoretical saturation is reached. 


\section{Instruments}

In this research, the methodology for gathering data was an in-depth semistructured interview with an open-ended question format. The interview process met Spradley (1979) suggested guidelines for ethnographic interviews. The interview's content validity certification is carried out according to standard qualitative analysis techniques Sarmento et al. (2014). After the review and discussion of previous transcript versions, certification of the material quality of the interview must be performed in full based on the following steps: i) preparation of the first edition of the transcript based on the particular objectives of the study, as well as review of the literature; (ii) my second and third author's evaluation of interview transcripts with thorough experience in semi-structured interview methods, (iii) confirmation of five experts for interview techniques and verification of the coefficient of Cohen (1968), (0.953 is an outstanding reliability value), (iv) reformulation based on feedback submitted to the second and third reviewers, v) a pilot study undertaken with my authors with government school coaches accredited by FAM vi) adaptation of the transcripts resulting from the reflection of the pilot study, vii) resubmission to my other two authors of this version of the transcripts. It finally culminated in the final version of the interview guide.

\section{Data Collection and Analysis}

These fourteen head coaches were interviewed over eight months at mutually convenient locations. The research participants were briefly informed about the purpose of the study, the risks, and the protection of the study conducted. At the same time, they are allowed to ask questions before signing the consent form. Participants were given opportunities to study the guide before engaging in the interview. Interviews ranging from 70 to 105 minutes were performed, and the digital file was later transcribed verbatim to be analysed according to evolved grounded theory (Corbin \& Strauss, 2015). The researcher uses the constant comparative method to establish concepts from the data through coding and interpretation at the same time (Taylor \& Bogdan, 1998). The constant comparative method combines theoretical sampling with systematic data collection, coding and analysis to develop an integrated, data-driven theory expressed in a form that is sufficiently clear for further testing (Glaser \& Strauss, 1967).

There are four steps of constant comparative methodology: i) comparing incidents applicable to each category, ii) integrating categories and their properties, iii) describing the theory, and iv) writing the theory. The researcher constantly sorts through the data collection, analyses and codes the knowledge during the four phases of the constant comparative method and enhances the theory generation through the theoretical sampling process. The advantage of using this approach is that the analysis starts with raw data; a substantive hypothesis will emerge from continuous comparisons. On the other hand, grounded theory is a labour-intensive assignment that allows the researcher to study data collection processes. 


\section{RESULTS}

Based on the analysis, the following seven new elements have emerged in the context of the Malaysian coaching process as compared to Cote and Gilbert, Effective Coaching Model: i) signature coaching, ii) risk management, iii) fun elements, iv) empowerment, v) spirituality, vi) life skills and vii) coaching intervention. Table 1 below shows some of the key themes that exist from the results of block codes from the interview.

Table 1

Key development themes that emerged from the interview

\begin{tabular}{|c|c|}
\hline $\begin{array}{l}\text { Signature } \\
\text { coaching }\end{array}$ & $\begin{array}{l}\text { - Many coaches mentioned that the recipe for success depends on how a coach uses } \\
\text { their coaching techniques. Expertise will only be gained with existing experience as } \\
\text { a player or coach. (MB7) } \\
\text { - Coach Sir Alex Ferguson has his coaching style, while Coach Pep Guardiola follows } \\
\text { his coaching style. Each has its coaching style that determines success. (MB2) } \\
\text { - The success of a coach depends on the planning according to their respective } \\
\text { coaching style expertise. } \\
\text { - Most successful coaches have their coaching ingredients learned from existing } \\
\text { experience. } \\
\text { - The coaching strategy expertise for each coach varies. Each has its way or recipe to } \\
\text { take the individual or team to a higher level. (MB1) } \\
\text { - When switching to another team, some coaches are carried away by their coaching } \\
\text { formula, and the results are still thriving. (MA1) } \\
\text { - In coaching program planning, implementing a coach's signature style or formula } \\
\text { is one of the features that can produce results when correctly used according to their } \\
\text { philosophies. } \\
\text {-I am a coach who wants all players to follow my pattern even in desperate situations. } \\
\text { Maybe I am a selfish person, but I have a reason for using this coaching style. (MB4) } \\
\text { - The democratic style coaching system is an option because it believes it is the most } \\
\text { appropriate for a development football team. This coaching style can be discussed } \\
\text { with the players at the same time. Coach instructions as well need to be followed. } \\
\text { (MB1, MB3, MB6, MB7) } \\
\text { - The players' maturity varies with each age; all three coaching styles are more } \\
\text { systematic in football development programs. (MB2, MA1, MA2, MB5) }\end{array}$ \\
\hline Fun element & $\begin{array}{l}\text { - To learn effectively, young players must enjoy what they are doing and enjoy variance } \\
\text { in their preparation and be forced to overcome various on-the-field situations. (MA1) } \\
\text { - Some coaches expressed some acknowledgement that kids consider game-like } \\
\text { activities to be more fun than many of the drills they have used. However, they also } \\
\text { kept a conviction that these drills must be completed. } \\
\text { - I can notice signs that these athletes' understanding is greatly increased, which helps } \\
\text { me apply in a football match. (MB6) } \\
\text { - Many athletes who apply fun tend to defy the odds and do not fear failure because } \\
\text { they love the challenge and feel and experience a deep bond. } \\
\text { - Honestly, in my observation, when there is an element of fun in the training program, } \\
\text { it helps my players mentally and physically. (MB3) } \\
\text { - When I give the flexibility so that my players feel happy while in this training } \\
\text { session, I make a fun game. We can see a total transformation in terms of their positive } \\
\text { character among players. (MB6) }\end{array}$ \\
\hline
\end{tabular}


Table 1 (continue)

\begin{tabular}{ll}
\hline Risk & - I am already familiar with the problem of infrastructure facilities and sports \\
management & equipment in this school, but I take this problem as a positive lesson as a challenge \\
that I have to face in my coaching process. (MB6) \\
- I do not care much about the existing sports facilities. I am just worried that this \\
constraint's consequences can cause serious injuries to players that can impede \\
individual and team performance. (MA1) \\
- A risk that happens to the player is not necessarily due to unsatisfactory basic \\
facilities, but sometimes it can happen due to the athlete's negligence. So, as a coach, \\
I need to be sensitive to all the knowledge of whatever risks our players face at any \\
time and act according to need. (MB2) \\
- Aware of the high risk of injury in sports due to outdated sports equipment. I always \\
monitor all sports equipment as safe to use with Quarter Master boys' help to inspect \\
the equipment carefully and report to me about any damage. (MB3)
\end{tabular}

Empowerment - As a coach, we cannot show our players that we are like iron nails instead of giving space to their opinions and expressing what they feel. (MA1)

- At the beginning of my coaching, I was a coach who adhered to 'follow my order and no question asked.' But over time, I saw my team seem to be playing with a movement that controlled. I realised this and started giving the players a little freedom and power to make rational decisions. (MB5)

- I often instruct my players to follow the game pattern I set before the competition, but I also give them the flexibility to make their own decisions in certain situations. This method has a good effect, probably because it does not feel controlled during the game. (MA2)

- If athletes have never been granted power as they have only been provided with the coach's information and answers, they may be unable to accept this burden of power. (MA2)

- The position of coaches is vital in enforcing empowerment because of their inability to let their power move on. Coaches will feel like they are not doing their job by not taking responsibility and not explicitly giving the athletes information. Like they are deprived of the 'strength' of the position of coaches. (MB3)

- I have my reasons why I give limited freedom to my players. In this development program, the maturity process of these high school students is still below the benchmark unless they have entered the level of elite players because most players use different coaching style methods. (MB4)

- Senior players aged 18 years and below who choose to make decisions or empower are more independent than players among 14 years and below. It may be due to the relatively extensive exposure to training and football competitions. While the players are under 16 years, the power is limited because the maturity to master a skill is still unclear (most coaches).

Spirituality - Even if we practice day and night hard, sometimes luck also plays a role. That is why the element of divinity, the ritual that gives inner strength before starting an activity. (MB2)

- Even if we prepare to face the opponent after going through excellent preparation, it still depends on the power of God. If he wants to give us victory, be thankful. If we lose even after playing brilliantly, I accept with an open heart. (MB6)

- One of the main factors that help me overcome this attitude problem is the religious values we apply from time to time. (MB7)

- Because my Sports School is a Cluster School of Excellence, my selected players are among the players who have good academic performance. These selected players of mine do have a high level of discipline. It may be because they are very vulnerable to many religious programs. (MA1) 
Table 1 (continue)

- This spiritual value has become a common practice in my coaching process. It is very much related to my players' discipline and behaviour. (MA1)

- Making sports a career, physical, mental and spiritual preparation is necessary to be confident when competing. To achieve goals, physical interests are paramount but mental skills also need to be given attention. (most coaches)

Life skills - As the head coach of football in the development program, my goal is to hone and produce quality players while producing skilled workers handling the best life. I would like to see my players succeed in life, not necessarily as football players but also in various aspects. (MB3)

- I am also proud to meet my former players everywhere outside the school area who have become police officers, firefighters, some who are government employees, and some who are businessmen. Despite not being a professional player but successful in life and becoming a successful human being is also a big achievement. It is one of my goals and satisfaction as a coach. (MB3)

- Shaping the players not only as quality players but also shaping their personality towards becoming successful students in the future. (MA1, MA2, MB2, MB5)

- It is impossible to produce all A-grade players and some after completing form five to continue their studies at college or university. No less, some continue to work after form five due to a lack of interest in continuing their studies. What they learned while participating in this football development program will help them develop for future undertakings. (MA2)

- I always have the support of my former players who are married and working now. They always come to school to help me financially to form the sports infrastructure of the school area. So I feel like it is not in vain what I thought for five years under my coaching program produced results, where the values of life taught made them useful human beings. (MB5)

- Although originally our intention in the development program was to form professional players, our goals may sometimes be less successful due to unavoidable factors. However, I feel that with the application of personality formation and the teaching of these good human values, either helping a player in self-improvement in playing career or those less fortunate as a football player will succeed in daily life as a successful and useful human being. (MB2)

Coaching

intervention

- Improvement can happen at any time, anywhere according to the objective needs of a coach. Sports coaches are responsible for improving various player results, including developing the technical and tactical skills needed to perform or play the game. (MA1)

- I will often monitor the needs of this intervention either during training or in the actual game. It depends on the situation of need. During the training, the intervention is maintained mainly by adapting and altering training activities based on the diagnosis made on the teams' results and the opposing teams. (MB6)

- In my coaching program, the intervention often takes place through meetings that are collective, individual or in small groups. (MA1)

- Usually, a week before the competition, we will adjust to the training exercises depending on the characteristics of the opposing team. I will try to improve on the weaknesses that exist during training from the results of the strengths available to the opposing team. (MB6)

- Sometimes, I have to make a lot of changes when facing a team that we first played. (MB1)

- We use other strategies, such as the fact that we have a designated player that also uses to relay information to reach out to their teammates, instant input, and gestures. (MA2) 
- Of course, we in the development program want to see an improvement in the achievement of these football athlete's day by day. Even though we achieved the Key Performance Indicator (KPI) that year, we still improve all the program's weaknesses throughout the program. We need to plan a more challenging Key Performance Indicator to achieve next year. (MA1)

Often, as a result of monitoring and observation by other coaches and me, we can assess existing weaknesses. (MB1)

\section{DISCUSSION}

The main objective of this comparative study is to identify the differences in the effective coaching process from the perspective of Malaysian culture compared to developing countries in the major developmental issues of football. While the fundamental components of an effective coaching process are the same in the coaching theory, the elements that distinguish coaching culture often play an important role in ensuring that a coaching process is effective in a football coaching program (Kassim \& Boardley, 2018). This argument is also confirmed by Lecrom and Dwyer (2013), in which cultural understanding is a phase of being appreciative and sensitive to cultural values, behaviours, lifestyles, practices and problem-solving. When individuals and organisations have come to this awareness to become more culturally sensitive, many find focused and personalised ways to obtain exposure to other cultures.

Researchers chose a comparison with Effective Coaching Model Cote and Gilbert (1990) on many factors across the suggested literature; including the International Council for Coaching Excellence and Association of Summer Olympic International Federations (ICCE \& ASOIF; 2012), firmly endorsing those coaching models as it is directed by several researchers as well as in the International Sport Coaching System (ISCF). Furthermore, any developed nations, such as the United States of America (USA), European countries, Japan, Poland and India, have been seen to have adopted ISCF standards for sports development in their respective countries. In reality, the International Golf Federation and the Professional Golfers Alliances (PGA Alliances) have tailored it to the particular needs of the International Golf Coaching System (IGCF) for golf coaching other than football (Kubischta, 2018).

The results show that there are seven new elements were emerged in the context of the Malaysian coaching process as compared to Cote and Gilbert, Effective Coaching Model: i) signature coaching, ii) risk management, iii) fun elements, iv) empowerment, v) spirituality, vi) life skills and vii) coaching intervention. Cote and Gilbert's basic definition of the Effecting Coaching Model is the consistent implementation of integrated professional, interpersonal, and intrapersonal knowledge to strengthen athletes the competence, confidence, connection, and character in specific coaching contexts. However, this 
model is illustrated in the diagram to enable the reader understand better (refer to Figure 2). Referring to the Cote and Gilbert (2009) model of effective coaching, it is found that most of the elements in this model emerged from the findings in this study; although the use of the elements is different it leads to the same meaning. However, seven elements are quite different from this model that appear according to Malaysian football development. Although it looks different, there is a possibility that the meaning inherent in this data is overlapping with the meaning stated in this model. Among them is signature coaching, where each coach has a different coaching style, and it depends on the training pattern learned. At the same time, they are athletes or the result of long coaching experience with the development football team. Most successful coaches have their coaching ingredients learned from existing experience. As most coaches said, the signature coaching style required players to clearly express and clarify certain thoughts or actions of coaching style preferences. The athlete's detailed description of the desired form of coaching conduct was of considerable significance.

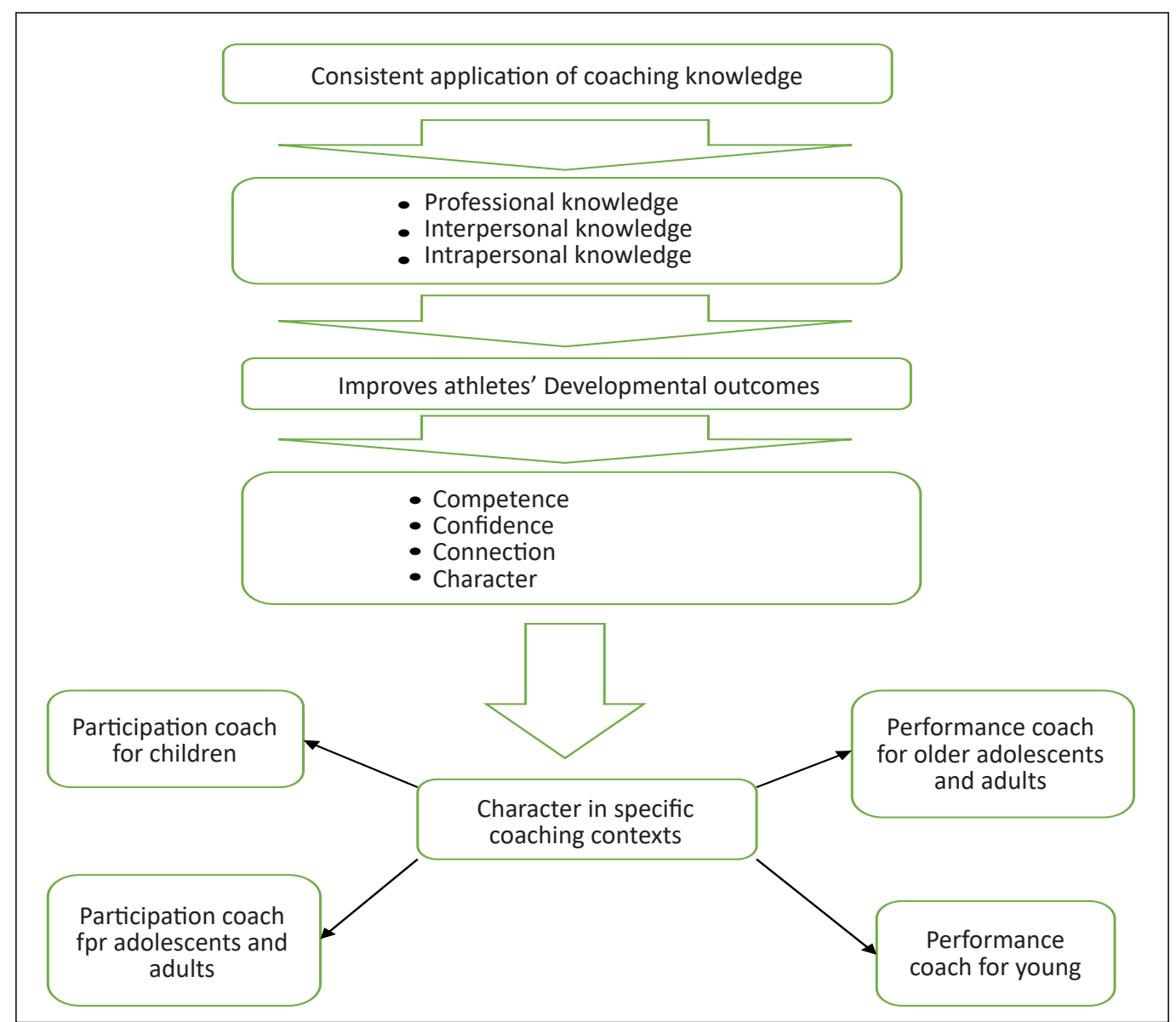

Figure 2. Adopted from Cote \& Gilbert Effective Coaching Model (2009) 
With more insight into the perceptions of the football player, their favourite signature coach is best appreciated. The greater the awareness, the greater the chance to apply trademark coaching style habits in practice sessions and competition (Carson \& Walsh, 2019). Football coaches can be better informed and optimally prepared to pursue the most efficient coaching style. It can be done by reflecting on the aspects that influence football coaches' expectations regarding players' contact with their coach and overall interest in football.

Apart from the signature coaching style, designing football coaching development programs such as fun elements become a priority in teaching periodisation. Most coaches understand that to learn successfully, and young players need to enjoy what they are doing. This young player has to enjoy differences in their preparation and be challenged to overcome many situations on the field. For starters, modified the rules every four to five minutes in small-sided games to encourage players to focus on the field themselves and produce good results. If young athletes are not having fun, they will eventually walk away, regardless of their talent or how good their team or coach is (Visek et al., 2018). In the Cote and Gilbert model, there is mention of implementing the element of fun in coaching; however, it leads to sports coaching for participants who participate in leisure activities. Although the coaches in this study stated that the fun element in coaching should be applied in every coaching activity, even though these players are from the age of 13 to 17 years, this development program's preparation leads to the preparation of performance athletes.

As athletes age and gain experience in training and skills, shifting from basic movements to physical fitness and from exploration of activity or sport to success, it becomes a crucial necessity for them to be able to spend vast quantities of time and considerable amounts of sweat equity in sport (Visek et al., 2018). As these coaches agree, most often, those, who have not developed a fun foundation quickly get disengaged. Hence, in the early stages of their sports growth, they experienced fun and joy in the sport. That fun was nurtured, designed and given the importance that these athletes become resilient moving from the inevitable defeats, errors and losses in the sport. Many athletes who apply fun tend to defy the odds and do not fear failure because they love the challenge and feel and experience a deep bond. They stay due to having fun, trying mastery, and performing at the best personal levels (Cote \& Gilbert, 2009).

The coaches involved in this development program should also be exposed to risk management knowledge in sports. This knowledge is often not revealed when this coach attends a short course organised by NFDP and may even be completely unaware of the importance of risk management. By incorporating appropriate monitoring practices and staying up to date with developments in the external world, coaches may reduce their programs' risk. As a result, coaches have a strong 
view of their teams' prospects. It will help coaches minimise possible risks while training their teams to play and is crucial to their successful development (Haag et al., 2016). The main criterion mentioned in the Cote and Gilbert model is that a coach needs to have specific knowledge in coaching. Although risk management knowledge can be categorised as specific knowledge, it is not highlighted in the model's description. Most likely, this risk management knowledge factor is basic knowledge that must be applied in western countries. While in the Malaysian perspective, the coaches see it as something beneficial for the development of sports, especially football.

Apart from risk management, another key development themes mentioned by the coaches in this study are empowerment. That is an athlete-centred approach that encourages a sense of self and offers athletes a role in decision-making and collaborative learning approaches (Solstad et al., 2018). Empowerment also enables athletes to believe that their thoughts are valued and motivates them to shoulder the responsibility for their development in success, which will create a larger degree of motivation (Solstad et al., 2018). This study also believe that coaching style plays a significant role in improving a sport's quality in the development program. As a result of this research, it is found that the internal psychological factors of the player's expectation, such as giving a little freedom in making decisions under this development program, should also be given attention. According to Solstad et al.
(2018), empowerment can be categorised in coaching leadership style under the scope of coaching philosophy. In the summary of the Cote and Gilbert models, this coaching philosophy has to do with interpersonal and intrapersonal knowledge. However, in this study, this key development becomes a priority in the coaching process.

According to Cote and Gilbert's model, there is an element of confidence that a person places in his or her ability to perform a particular task to achieve a particular outcome successfully. For the opinion given by the coach in this study, to strengthen the element of confidence in a person, the element of spirituality is very important in universal human life. According to Malaysian culture, the average student equivalent player has a moderate academic qualification. The study also found that athletes with less academic exposure have a negative attitude towards the behaviour. The only key development theme that can help overcome these players' attitudes is through beliefs and demands on religion (Nik Abdullah et al., 2015). Therefore, applying spirituality is very appropriate in the players' needs, especially in the Malaysian development program. The need for spirituality has to be standardised to plan coaching development programs to align with the coaches' opinions.

The importance of life skills in teaching and learning is also a priority in this study's findings. The coach realises that not all trained players can be excellent players and absorbed in the national or Malaysian League team. Of course, some drop out, 
and these coaches hope that the learning resulting from the coaching program for five years should be used properly to become valuable human beings. These coaches want to see the life skills learned during this coaching to succeed even in different fields. It is one of the outcomes of the development program that is the hope of every coach. On the other hand, looking at the Cote and Gilbert model, there is a mention of the connection element in the outcome study's scope. The connection element may carry deep meaning, but it leads to a relationship between the athlete and the coach. In comparison, the coaches in this study want to see how these life skills can form athlete relationships with each community that can be a factor in their success.

The last key development theme to be mentioned in this study is coaching intervention. Looking at the effective coaching model of Cote and Gilbert, it is not called a cyclic model. Maybe Cote and Gilbert want to show coaching effectiveness according to the group context, which varies according to the coaches' needs. Instead, in this study, researchers want to see effective coaching in this coaching process in cyclic form. Since this development program is term, each program result has weaknesses and improvements. Therefore, the study results show that it is necessary to implement a coaching intervention plan during the offseason. Only in this way it can evaluate the trial and error of the effectiveness of a program for the future (Cote \& Gilbert, 2009).
In conclusion, it is common for a sports organisation to refer to a coaching model as a guide in a coaching program. The coaching model that is the reference is also the result of the findings of past studies. This model may be closely related to the method of study in certain countries. Although a past coaching model can be used as a basis in a coaching program, according to the study, each country's coaching culture has different influences according to the developmental pattern of an individual in different community groups. Therefore, researchers would like to see the differences between the existing key development themes by comparing the Cote and Gilbert Models. The results of this study are intended to offer feedback to the Football Association of Malaysia (FAM) and the National Football Development Program (NFDP) so that all of the findings may be incorporated into the football coaching curriculum under the development program. This finding is also expected to help all coaches involved in football development understand the development themes in the Malaysian culture to be absorbed in their coaching process.

\section{ACKNOWLEDGEMENT}

The authors would like to thank the anonymous participants for their cooperation and time in providing the researcher with all the needed information.

\section{REFERENCES}

Carson, F., \& Walsh, J. (2019): Are we there yet? A signature pedagogy for sports coaching. Annals 
of Leisure Research, 24(2), 1-7. https://doi.org/ 10.1080/11745398.2019.1672570

Cohen, J. (1968). Weighted Kappa - a nominal scale agreement with provision for scaled disagreement or partial credit. Psychological Bulletin, 70(4), 213-220. https://doi.org/10.1037/ h0026256

Corbin, J., \& Strauss, A. (2015). Basics of qualitative research. Sage.

Cote, J., \& Gilbert, W. (2009). An integrative definition of coaching effectiveness and expertise. International Journal of Sports Science and Coaching, 4(3), 307-322. https:// doi.org/10.1260/174795409789623892

Crawford, A., Zucker, T., Horne, B. V., \& Landry, S. (2017). Integrating professional development content and formative assessment with the coaching process: The Texas School Ready Model, Theory into Practice, 56(1), 56-65. https://doi.org/10.1080/00405841.2016.1241945

Creswell, J. W. (2014). Research design: Qualitative, quantitative and mixed methods approaches (4th ed.). Sage.

Fairs, J. R. (1987). The coaching process: The essence of coaching. Sports Coach, 11(1), 17-19.

Flett, M. R., Carson Sackett, S., \& Camire, M. (2016). Understanding effective coaching: Antecedents and consequences. In R. Thelwell, C. Harwood, \& I. Greenlees (Eds.), The psychology of sports coaching: Research and practice (pp. 156-169). Routledge. https://doi.org/10.1080/21640629.20 18.1459356

Franks, I. M., Sinclair, G. D., Thompson, W., \& Goodman, D. (1988). Analysis of the coaching process. Science Periodical on Research and Technology in Sport, January, 1-12.

Glaser, B., \& Strauss, A. (1967). The discovery of grounded theory. Aldine Publishing Co.

Haag, T.-B., Mayer, H. M., Schneider, A. S., Rumpf, M. C., Handel, M., \& Schneider, C. (2016). Risk assessment of back pain in youth soccer players. Research in Sports Medicine, 24(4), 395-406. https://doi.org/10.1080/15438627.2016.1222275

Holmes, B., (2018, December 10). Business of sports: Putting Malaysian football back on the road. The Edge Malaysia. https://www.theedgemarkets. com/article/business-sports-putting-malaysianfootball-back-road

International Council for Coaching Excellence and Association of Summer Olympic International Federations. (2012). International Sport Coaching Framework. Human Kinetics. https:// www.icce.ws/_assets/files/news/ISCF_1_ aug_2012.pdf

Karim, Z. B. A., \& Razak, N. (2018). Lesson learned from coaches of Malaysia National Football Development Program (NFDP): Preferred career development pathway and accredited coaching course. International Journal of Academic Research in Business and Social Sciences, 8(6), 1069-1082. https://doi.org/10.6007/IJARBSS/ v8-i6/4302

Kassim, M. (2014). Towards the reflective football coach from qualitative analysis. Journal of Human Sport \& Exercise, 9(Proc1), 249-256. http://doi.org/10.14198/jhse.2014.9.Proc1.06

Kassim, M., \& Boardley, I. (2018). 'Athletes' perceptions of coaching effectiveness and athlete-level outcomes in team and individual sports: A cross-cultural investigation. The Sport Psychologist, 32(3), 189-198. https://doi. org/10.1123/tsp.2016-0159

Kassim, M., \& Che Ali, N. R. (2015). An effective coaching through "coaching model". Journal of Scientific Research and Development, 2(13), 158-164.

Kubischta, F, (2018). The coach development framework for the International Ice Hockey Federation [Doctoral thesis, University of Applied Sciences, Haaga-Helia]. https://www. theseus.fi/handle/10024/156802 
Lebar, O. (2014). Penyelidikan kualitatif: Pengenalan kepada teori dan metod Edisi Keempat [Qualitative research: An introduction to theory and methods Fourth Edition]. Penerbit Universiti Pendidikan Sultan Idris.

Lecrom, C. W., \& Dwyer, B. (2013). Plus sport: The impact of a cross-cultural soccer coaching exchange. Journal of Sports for Development, 1(2), 1-16.

Lyle, J. (2002). Sports coaching concepts: A framework for coaches' behavior. Routledge.

Neuman, J. (2006). Protection through participation: Young people affected by forced migration and political crisis (Refugee Studies Centre Working Paper No. 20). University of Oxford.

Nik Abdullah, N. S., Maamor, S., Abdul Ghani, A., Abd. Wahab, N., Ahmad Razimi, M. S., Aziz, A. B., \& Elias, N. H. (2015). Kepentingan elemen kerohanian dalam perlaksanaan aktiviti di MRSM Ulul Albab: Kajian kes di MRSM Gemencheh, Negeri Sembilan [The importance of spiritual elements in the implementation of activities at MRSM Ulul Albab: A case study at MRSM Gemencheh, Negeri Sembilan]. Journal of Global Business and Social Entrepreneurship, 1(2), 77-88.

Patton, M. Q. (2002). Qualitative research and evaluation methods (3rd ed.). Sage.

Sarmento, H., Pereira, A., \& Anguera, M. T. (2014). The coaching process in football- A qualitative perspective. Journal of Sports Science Medicine, 3(1), 9-16.
Sherman, C., Crassini, B., Maschette W., \& Sands R. (1997) Instructional sports psychology: A reconceptualization of sports coaching as instruction. International Journal of Sports Psychology, 28(2), 103-125.

Solstad, B. E., Ivarsson, A., Haug, E. M., \& Ommundsen, Y. (2018). Youth sport coaches' well-being across the season: The psychological costs and benefits of giving empowering and disempowering sports coaching to athletes. International Sport Coaching Journal, 5(2), 124-135. https://doi.org/10.1123/iscj.2017-0026

Spradley, J. P. (1979). The ethnographic interview. Holt, Rinehart \& Winston.

Strauss, A., \& Corbin, J. (1990). Basic of qualitative research: Grounded theory, procedures, and techniques. Sage.

Strauss, A., \& Corbin, J. (1998). Basics of qualitative research: Techniques and procedures for developing grounded theory (2nd ed.). Sage.

Taylor, S. J., \& Bogdan, R. (1998). Introduction to qualitative research methods: A guidebook and resource (3rd ed.). John Wiley \& Sons Inc.

Teong Kim earns RM175,000 a month-Syed Saddiq. (2018, September 27). Bernama.com. http:// www.bernama.com/en/news.php?id=1647262

Visek, A. J., Mannix, H., Chandran, A., Cleary, S. D., McDonnell, K., \& DiPietro, L. (2018). Perceived importance of the fun integration theory's factors and determinants: A comparison among players, parents, and coaches. International Journal of Sports Science \& Coaching, 13(6), 849-862. https://doi.org/10.1177/1747954118798057 
